\title{
Sağlık arama davranışı olarak internet kullanımını inceleyen bir araştırma
}

\author{
A research on internet use as health seeking behavior
}

\author{
Abdullah Buğra Can, Ebru Sönmez, Ferhad Özer, Gözde Ayva, Halit Bacı, Hazel \\ Ezgi Kaya, Ozan Uyan, Gülnaz Ulusoy, Nuray Öğütçü*, Dilek Aslan
}

Tıp Fakültesi (İnt. Öğr. A. B. Can, İnt. Öğr. E. Sönmez, İnt. Öğr. F. Özer, İnt. Öğr. G. Ayda, İnt. Öğr. H. Bacı, İnt. Öğr. H. E. Kaya, İnt. Öğr. O. Uyan), Halk Sağlığı Anabilim Dalı (Arş. Gör. Dr. G. Ulusoy, Arş. Gör. Dr. N. Öğütçü, Prof. Dr. D. Aslan), Hacettepe Üniversitesi Tıp Fakültesi, TR-06230 Ankara

\begin{abstract}
Özet
Amaç. Bu çalışmada, sağlığı ilgilendiren konularda kullanımda olan ve belirlenmiş kriterlere göre seçilmiş bazı web sitelerinin şekil, içerik ve kurumsallık gibi özelliklerinin araştırılması amaçlanmıştır. Yöntem. Tanımlayıcı tipte olan bu araştırmada, Türkiye'de en sık kullanılan arama motoruna vücut sistemleri ile ilgili semptomlara ilişkin seçilmiş anahtar sözcükler verildiğinde ulaşılan web siteleri değerlendirilmiştir. Anahtar sözcükler, her bir semptom için dört adet olmak üzere "semptomun kendisi", "semptom ve koruma", "semptom ve tanı", "semptom ve tedavi" şeklinde belirlenmiştir. Anahtar sözcükler, araştırmacılar tarafından belirlenen vücut sistemleri (sinir, sindirim, kardiyovasküler, solunum, kas-iskelet, endokrin, üriner, erkek genital, kadın genital, deri ve lenfatik sistemleri) ile ilgili araştırmacıların çalıştıkları hastanenin ilgili bölümlerinin baş asistanlarına ilgilendikleri sistemle ilgili "En sık gördüğünüz beş semptomu söyler misiniz?" sorusuna verilen yanıtlara göre belirlenmiştir. Baş asistanlar tarafından ifade edilen anahtar sözcükler listelenmiş, araştırmacılar tarafından kura çekilerek beş semptom içinden üç semptom seçilmiştir. Her bir anahtar sözcük için anahtar sözcük yanında virgül kullanılarak üç farklı ek sözcük kullanılmıştır ("anahtar sözcüğün kendisi”, "anahtar sözcük, korunma”, "anahtar sözcük, tanı”, “anahtar sözcük, tedavi”). Bir semptom için toplam dört farklı arama yapılmıştır. Toplamda, her bir sistem için 12 anahtar sözcük incelenmiştir. Her bir anahtar sözcük için reklam kullanarak üst sırada olan siteler hariç ilk 5 site değerlendirilmiştir. Sonuç olarak, ilk aşamada her bir sistem için toplam 60 , on sistem için ise 600 web sitesi incelenmiştir. Sitelerde çakışmalar dışarıda bırakıldığında toplamda 475 web sayfası incelenmiştir. Veri girişi ve analizi için SPSS programı kullanılmıştır. Bulgular. Araştırmaya dahil edilmiş sitelerin \%92'sinde kanıta dayalı hiçbir bilgi olmadığ 1 bulunmuştur. Bununla beraber sağlıkla ilgili bilgi veren mevcut sitelerin \%40,6'sında hekime veya sağlık çalışanına yönlendirme olmaması dikkat çekmiştir. Ayrıca sitelerin \%65,9'u reklam içermektedir. Araştırmacıların sadece \%9,7'si web sayfalarını hastalarına önereceklerini belirtmişlerdir. Reklam içerme ve sponsor olması araştırmacıların öneri seçeneklerini etkilemiştir. Sonuç. Sonuç olarak sağlık/hastalıkla ilgili web sitelerinin kullanıcıları için ticari kaygılardan bağımsız olarak yararlı olabilmeleri için gelişmeye/iyileşmeye gereksinimi bulunmaktadır.
\end{abstract}

Anahtar sözcükler: Semptom, sağlık arama davranışı, internet

\begin{abstract}
Aim. In this study, "active" web sites related to health which were selected due to determined criteria have been evaluated in terms of formal, contextual and institutional characteristics. Methods. In this descriptive study, web sites which have been accessed when selected key words on the most frequently seen symptoms of the diseases were entered into the most frequently used search engine in Turkey. Four key words for each symptom were determined like "symptom alone", symptom and prevention", "symptom and diagnosis", "symptom and treatment". Researchers determined the most frequently seen symptoms of the neural, gastro intestinal, cardiovascular, respiratory, musculo-skeletal, endocrine, urinary, male genital, female genital, skin and lymphatic systems due to the answers of chief residents' working at a university hospital to the question "Would you kindly say the most frequently seen five symptoms in your daily practice?". All stated symptoms were listed by the researchers and three of five for each system were selected
\end{abstract}


by random. For each key word, four searches were completed (the key word itself as well as three more searches using; "key word, prevention", "key word, diagnosis", "keyword, treatment". Four different searches were done for each symptom which equals to 12 searches for one system. The first five web sites excluding the web sites used advertisements were investigated for one search. In the end, 60 web sites for each system and 600 web sites for all systems were assessed in the first run of the study. After exclusion of the duplicated sites, 475 web sites were included in the study. SPSS program was used for data entry and analysis. Results. Ninety two percent of the web sites did not include evidence based information. Besides, $40.6 \%$ of the current sites did not direct their users to either physicians or health professionals. Sixty five percent nine of the accessed web sites included advertisements. Only $9.7 \%$ of the researchers stated their possibility to recommend the web sites to their patients. The advertisement and sponsor relationships influenced their recommendation status. Conclusion. Web sites' related to health/diseases need improvement (s) in order to be useful for their users in the community independently from commercial expectations.

Keywords: Symptom, health seeking behavior, internet

Geliş tarihi/Received: 25 Ağustos 2014; Kabul tarihi/Accepted: 12 Kasım 2014

\author{
*İletişim adresi: \\ Dr. Nuray Öğütçü, Halk Sağlığı Anabilim Dalı, Hacettepe Üniversitesi Tıp Fakültesi TR-06100 \\ Ankara. E-posta: nurayogutcu@ hacettepe.edu.tr
}

\title{
Giriş
}

İnternet, dünyadaki kişisel yada kurumsal bilgisayar ağlarını birbirine bağlayan elektronik iletişim ağıdır [1]. Türk Dil Kurumu'nun tanımına göre dilimizdeki karş1lığı "genel ağ"; birbirine bağlı bilgisayar ağlarının tümüdür [2].

Ülkemizde Türkiye İstatistik Kurumu'nun 2014 verilerine göre bilgisayar ve internet kullanım sıklığının en yüksek olduğu yaş grubu 16-24 yaş aralığıdır. On beş yaş üzeri tüm yaş gruplarında erkekler arasında kullanım sıklığı kadınlardan daha yüksektir [3].

İnternet kullanımının yaygınlaşması sağlık alanında bilgi edinme amacı ile kullanımını da artımaktadır [4]. Bu değişime paralel olarak, sağlıkla ilgili web sayfalarının da kullanımını artırmaktadır. Sağlık sitelerinin tanı, tedavi amaçlı hizmet verdiklerine dair bilgiler bulunmaktadır [4-6].

İnterneti sağlıkla ilgili sık kullananlar hastalıklarla ilgili bilgi edinmek amaçlı kullanmaktadırlar. Amerika Birleşik Devletleri (ABD) kaynaklı bir araştırmaya katılan 1289 hastadan \%65'inde internet erișimi olduğu ve bunların \%74'ünün (toplamın \%48,1'i) sağlıkla ilgili bir konuda bilgi edinmek amacı ile internete başvurdukları bildirilmiştir [7]. Örnekte olduğu gibi sağlık ve sağlık bakımı amaçlı kullanımının yaygınlığı tam olarak açık değildir [8].

Sağlık alanında web sitelerinin artması rekabeti arttırmış, içeriklerinin doğruluğu, güncelliği, referansları kadar kullanıcıların bilgilerinin güvenliği, ürün ve hizmetlere yönlendirmeler, reklam ve sponsorluk ilişkileri gibi konularda eleştiriler ortaya çıkmıştır. Aynı zamanda içeriklerindeki yanıltıcı bilgilerin kullanıcılara zarar verebilmesi, denetim yetersizliği ortamdaki bilgilerin güvenirliğinin azalmasına neden olmuştur. Bu durumda tıbbi bilgilerin web sitelerinde kullanımı etik bir sorunda oluşturmaktadır. [9].

Sağlık çalışanlarının hastayla birebir görüşmeden web sitelerinde tedavi önerilerinde bulunmalarının doğuracağı sonuçlar önemli bir tartışma konusudur [7].

Yukarıda belirtilen gerekçeler nedeniyle bu çalışmada, sağlığı ilgilendiren konularda kullanımda olan ve belirlenmiş kriterlere göre seçilmiş bazı web sitelerinin şekil, içerik ve kurumsallık gibi özelliklerinin araştırılması amaçlanmıştır. 


\section{Gereç ve yöntem}

Tanımlayıcı tipteki bu araştırma "Google" arama motoru kullanılarak gerçekleştirilmiştir. Arama motoruna anahtar sözcüklerin verilişi ve aratılması 22-25 ve 31 Temmuz 2014 tarihlerinde gerçekleştirilmiştir. Verilerin girişi ve analizi için IBM SPSS Statistics 22 paket programı kullanılmıştır. Araştırmanın verileri bilimsel amaçlar dışında kullanılmamıştır ve araştırma için taranan sitelerin adresleri ve içerik bilgileri saklı tutulmuştur.

\section{Araştırmanın evreni, seçim süreci, dahil edilme kriterleri}

a) Araştırmanın evrenini "Google" arama motorunda anahtar sözcükler verilerek yapılan taramada listeye dahil olan siteler oluşturmaktadır. Araştırmaların "Google" arama motorunda yapılma nedeni; Türkiye'de kullanılan en sık beş arama motoru sitesi listesine göre ülkemizde en s1k kullanılan arama motoru sitesi \%95,9 ile Google, ikinci \%2,3 ile Yandex, üçüncü \%1 ile Bing, dördüncü $\% 0,4$ ile Yahoo'nun olmasıdır [10].

b) Araştırma kapsamında kullanılan sitelerin dahil edilme kriteri, "Google" arama motorunda yapılan sağlık bilgilerini arama sürecinde listede üst sırada çıkan ilk beş sonuç içerisinde yer almaları ve metin içerikli siteler olmalarıdır. Araştırma kapsamında kullanılan sitelerin dahil edilmeme kriterleri ise; Google reklamları içerisinde yer almamaları, sadece görsel ve video içerikli site olmaları, açılan sitelerin sosyal medyanın bir uzantısı olmaları ve pdf-word gibi belgeler olmalarıdır.

c) Her bir anahtar sözcük için anahtar sözcük yanında virgül kullanılarak üç farklı ek sözcük kullanılmıştır (semptom; "semptom, korunma", "semptom, tanı", "semptom, tedavi"). Her bir anahtar sözcük için toplam dört farklı arama yapılmıştır.

d) Anahtar sözcüklerin seçimi için, araştırmacılar tarafından belirlenen vücut sistemleri (sinir, sindirim, kardiyovasküler, solunum, kas-iskelet, endokrin, üriner, erkek genital, kadın genital, deri ve lenfatik sistemleri) ile ilgili Hacettepe Hastanelerinde çalışan baş asistanlara kendi ilgilendikleri sistemle ilgili "En sık gördüğünüz beş semptomu söyler misiniz?" sorusuna verilen yanıtlar kullanılmıştır. Baş asistanlar tarafindan ifade edilen anahtar sözcükler listelenmiş, araştırmacılar tarafindan kura çekilerek beş semptom içinden üç semptom seçilmiştir.

e) Toplamda, her bir sistem için 12 anahtar sözcük incelenmiştir. Her bir anahtar sözcük için reklam kullanarak üst sırada olan siteler hariç ilk 5 site değerlendirilmiştir. Sonuç olarak, ilk aşamada her bir sistem için toplam 60 , on sistem için ise 600 web sitesi incelenmiştir. Sitelerde çakışmalar dışarıda bırakıldığında toplamda 475 web sayfası incelenmiştir. Veri girişi ve analizi için SPSS programı kullanılmıştır.

\section{Araştırmanın değişkenleri}

İnternet sitesinin kanıta dayalı bilgileri içerip içermediği, bilgilerinin güncel olup olmadığı, uzman görüşü içerip içermediği, hekim-sağlık çalışanına yönlendirme olup olmadığı, korumaya yönelik bilgiler içerip içermediği, teşhis ile ilgili yönlendirme olup olmadığı, tedavi önerip önermediği, tedavi önerilmesi durumunda ticari kaygıların öne çıkarılıp çıkarılmadığı, sponsor ilişkisinin olup olmadığı, kurumsal kimliğinin olup olmadığ1 (.edu, gov, .com gibi), resim-grafik-şema gibi görsellerin kullanılıp kullanılmadığı, reklam içeriğinin bulunup bulunmadığı, soru-yanıt olanağı gibi interaktif bir kurgusu olup olmadığı, sosyal medyaya yönlendirme olup olmadığı araştırmanın kimi değişkenleridir.

Araştırma kapsamında ayrıca; araştırmacıların da görüş ve değerlendirmelerine yer verilmiştir. Araştırmacılar; web sitesinin kurumsal bilgisinin olup olmaması, resmi bir kurumu temsil edip etmemesi, web sitesinde kaynak/referans bulunup bulunmamas1, 
kanıta dayalı bilgi içerip içermemesi, uzman görüşü içerip içermemesi, web sitesinde tıp dergisi olup olmaması gibi kriterler üzerinden web sitesinin güvenilir olup olmadığına dair görüşlerini oluşturmuşlardır. Bu konularda pozitif olan siteler "güvenilir", pozitif olmayan siteler ise "güvenilir değil" şeklinde değerlendirilmiştir. Araştırmacılar, siteleri başkalarına önerip önermeyeceklerine dair de görüş oluşturmuşlardır. Güvenilir buldukları siteleri başkalarına önerme eğiliminde olduklarını ve güvenilir bulmadıkları siteleri de başkalarına önerme eğiliminde olmadıklarını belirtmişlerdir. Bu yaklaşımlar Tablo 3, 4 ve 5 'te sunulmuşstur.

\section{Bulgular}

Web sayfalarının \%52'sinde ( $\mathrm{n}=247)$ resim, grafik, şema kullanımı, \%37,7'sinde $(\mathrm{n}=179)$ interaktif kurgu, \%50,5'inde $(n=240)$ sosyal medyaya yönlendirme ve \%7,6'sinda $(n=36)$ hasta bilgilerinin paylaşıldığı saptanmıştır (Tablo 1).

Tablo 1. İncelenen web sayfalarının şekilsel bazı özellikleri (Temmuz 2014).

\begin{tabular}{lll}
\hline Özellik & Sayı & \% \\
\hline Resim, grafik, şema kullanılma durumu & & \\
Evet & 247 & 52 \\
Hayır & 228 & 48 \\
\hline İnteraktif kurgusunun bulunma durumu & & \\
Evet & 179 & 37,7 \\
Hayır & 296 & 62,3 \\
\hline Sosyal medyaya yönlendirme durumu & & \\
Evet & 240 & 50,5 \\
Hayır & 235 & 49,5 \\
\hline Hasta bilgilerinin paylaşılma durumu & & \\
Evet & 36 & 7,6 \\
Hayır & 439 & 92,4 \\
\hline Toplam & $\mathbf{4 7 5}$ & $\mathbf{1 0 0 , 0}$ \\
\hline & & \\
& &
\end{tabular}

Tablo 2. İncelenen web sayfalarının içeriklerine ilişkin bazı özellikleri (Temmuz 2014).

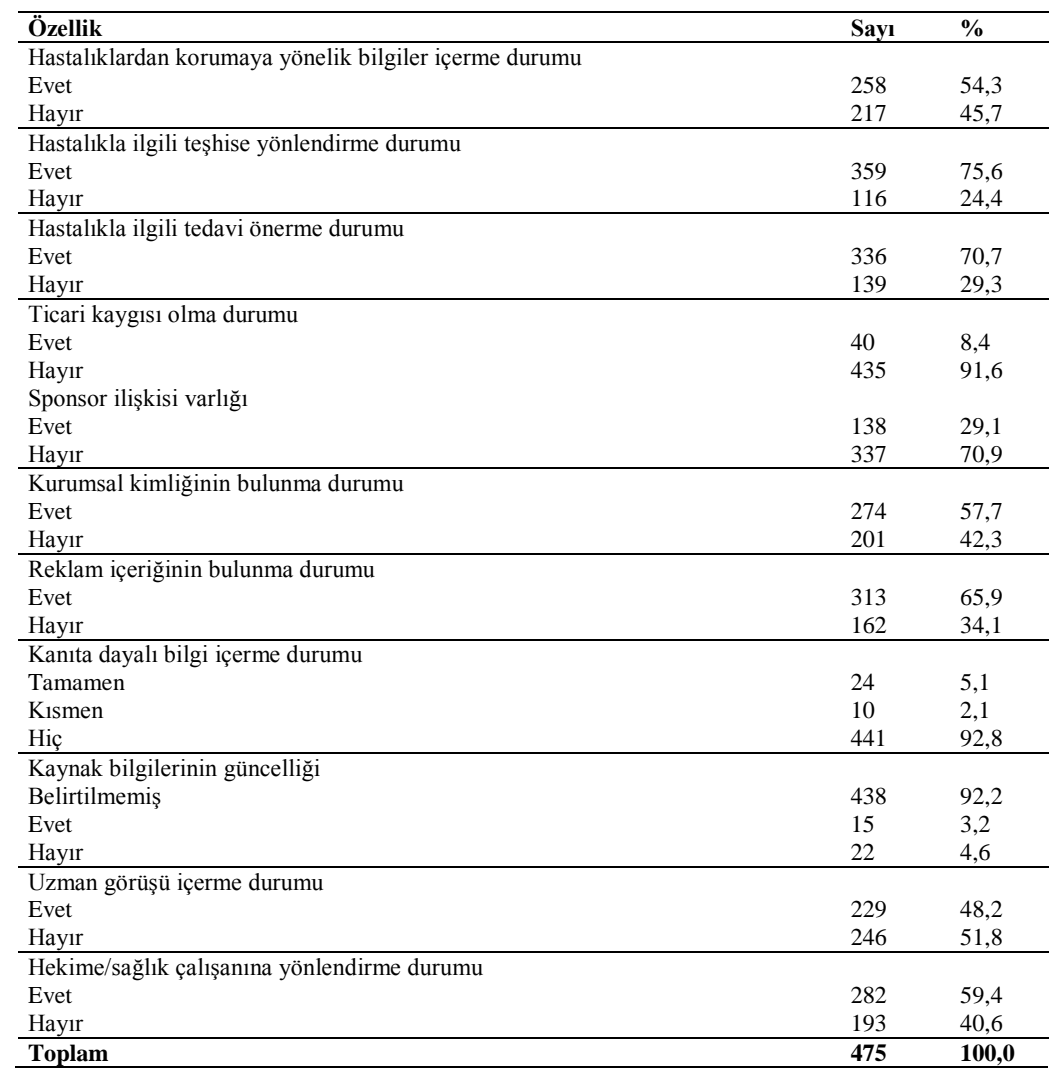


Web sayfalarının \%54,3'ünün (n=258) hastalıklardan korumaya yönelik bilgiler içerdiği, Yine web sayfalarının, \%75,6'sının $(n=359)$ hastalıkla ilgili teşhise yönlendirdiği, $\% 70,7$ 'sinin $(n=336)$ hastalıkla ilgili tedavi önerdiği saptanmıştır. Sitelerin \%8,4'ünün $(\mathrm{n}=40)$ ticari kaygısı olduğu düşünülmüştür.

Araştırma kapsamında incelenen web sayfalarının \%29,1'inin $(\mathrm{n}=138)$ sponsor ilişkisi içerdiği, \%57,7'sinin ( $n=274)$ kurumsal kimliğinin olduğu ve \%65,9'unun da $(n=313)$ reklam içeriği bulunduğu saptanmıştır.

Web sayfalarının \%92,8'inin (n=441) kanıta dayalı bilgi hiç içermediği, \%92,2'sinin $(\mathrm{n}=438)$ kaynak bilgilerinin güncelliğini belirtmediği, \%51,8'inin $(\mathrm{n}=246)$ uzman görüşü içermediği saptanmıştır. Sitelerin \%59,4'ünün (n=282) hekime/sağlık çalışanına yönlendirmesi olduğu belirlenmiştir (Tablo 2).

Tablo 3. Araştırmacıların web sayfalarını herhangi bir kişiye/hastalarına önermeyi düşünme durumu (Temmuz 2014).

\begin{tabular}{lll}
\hline Araştırmacının siteyi hastalarına önerme durumu & Sayı & $\mathbf{\%}$ \\
\hline Önermeyi düşünür, çünkü; & $\mathbf{4 6}$ & $\mathbf{9 , 7}$ \\
$\begin{array}{l}\text { Güvenilir, kurumsal bilgi, sağlık bakanlığı sitesi, kaynak bulunması, kanıta dayalı } \\
\text { bilgi içermesi, uzman görüşü olması, tıp dergisi }\end{array}$ & 35 & 71,4 \\
Bilgilerin açıklayıcı olması, dilinin açık olması, doğru yönlendirme, korumaya & 11 & 28,6 \\
yönelik bilgi içermesi & & \\
\hline Önermeyi düşünmez, çünkü; & $\mathbf{3 5 4}$ & $\mathbf{7 4 , 5}$ \\
Güvenilir değil, kanıtsı, bilim dışı, kaynak yok, sağlık sitesi değil & 199 & 56,2 \\
Yetersiz kaynak, güncel olamayan bilgi, hekime yönlendirme olmayışı, yanlış & 122 & 34,5 \\
yönlendirme, anlaşılırlığı, uzman görüşü olmayışı & \\
Reklam amaçlı, çıar amaçlı kullanma durumu & 20 & 5,6 \\
Diğer* & 13 & 3,7 \\
\hline Kararsız, çünkü; & $\mathbf{2 2}$ & $\mathbf{4 , 6}$ \\
Olumlu yönde kararsı olma durumu & 11 & 50,0 \\
Olumsuz yönde kararsız olma durumu & 11 & 50,0 \\
Fikri yok & 53 & 11,2 \\
\hline Toplam & $\mathbf{4 7 5}$ & $\mathbf{1 0 0 , 0}$ \\
\hline *Hasta bilgilerinin paylaşılma durumu, kurumsal olmama durumu, sosyal medyaya & \\
yönlendirmeme durumu, forum-interaktif olma durumu. & \\
\hline
\end{tabular}

Araştırmacıların \%74,5'inin ( $\mathrm{n}=354)$ siteyi hastalarına önermediği, \%11,2’sinin $(n=53)$ fikir belirtmediği, \%4,6'sının (n=22) kararsız olduğu saptanmıştır.

Siteleri önerme nedenleri arasında en sık "siteyi güvenilir bulma, sitenin kurumsal bilgi içermesi, kanıta dayalı bilgi içermesi, uzman görüşü içermesi" yer almıştır (35 site, \%71,4). Siteleri önermeme nedenleri arasında ise en sik "siteye güvensizlik, sitede kanıt olmaması ve sitenin bilim dışı olması, kaynak olmayışı, sağlık sitesi olmayışı" belirtilmiştir (199 site, \%56,2) (Tablo 3).

Tablo 4. Web sitelerinin reklam içerme durumuna göre araştırmacının web sitelerini önerme durumu (Ankara, Temmuz 2014).

\begin{tabular}{lllllll}
\hline \multirow{2}{*}{ Reklam içerme durumu } & \multicolumn{6}{c}{ Araştırmacını web sitelerini önerme durumu } \\
\cline { 2 - 7 } & Evet & \multicolumn{4}{c}{ Hayır } & \multicolumn{3}{c}{ Toplam } \\
\hline \multirow{3}{*}{ Evet } & Sayı & Yüzde & Sayı & Yüzde & Sayı & Yüzde* \\
Hayır & 22 & 7,0 & 291 & 93,0 & 313 & 65,9 \\
\hline Toplam & 24 & 14,8 & 138 & 85,2 & 162 & 34,1 \\
\hline *Sütun yüzdesidir, diğerleri satır yüzdesidir. & $\mathbf{4 6}$ & $\mathbf{9 , 6}$ & $\mathbf{4 2 9}$ & $\mathbf{9 0 , 4}$ & $\mathbf{4 7 5}$ & $\mathbf{1 0 0 , 0}$ \\
\hline
\end{tabular}

Reklam içeriği bulunmayan web sitelerinin \%14,8'i $(n=24)$ araştırmacılar tarafindan tamamen ya da kısmen önerilirken, reklam içeriği bulunan web sitelerinin \%7,0'1 (n=22) araştırmacılar tarafından tamamen ya da kısmen önerilmektedir. Bu fark istatistiksel olarak anlamlıdır (Ki kare=7,399; $\mathrm{p}=0,007)($ Tablo 4). 
Tablo 5. Web sitelerinin sponsor ilişkisi bulunma durumuna göre araştırmacının web sitelerini önerme durumu (Ankara, Temmuz 2014).

\begin{tabular}{lllllll}
\hline \multirow{2}{*}{ Sponsor ilişkisi olma durumu } & \multicolumn{6}{c}{ Araştırmacının web sitelerini önerme durumu } \\
\cline { 2 - 7 } & Evet & \multicolumn{4}{c}{ Hayır } & Toplam \\
\hline \multirow{3}{*}{ Evet } & Sayı & Yüzde & Sayı & Yüzde & Sayı & Yüzde* \\
Hayır & 12 & 8,7 & 126 & 91,3 & 138 & 29,1 \\
\hline Toplam & 34 & 10,1 & 303 & 89,9 & 337 & 70,9 \\
\hline *Sütun yüzdesidir, diğgerleri satır yüzdesidir. & $\mathbf{4 6}$ & $\mathbf{9 , 6}$ & $\mathbf{4 2 9}$ & $\mathbf{9 0 , 4}$ & $\mathbf{4 7 5}$ & $\mathbf{1 0 0 , 0}$ \\
\hline
\end{tabular}

Sponsor ilişkisi bulunmayan web sitelerinin \%10,1'i $(\mathrm{n}=34)$ araştırmacılar tarafindan tamamen ya da kısmen önerilirken, sponsor içeriği bulunan web sitelerinin \%8,7'si $(\mathrm{n}=12)$ araştırmacılar tarafından tamamen ya da kısmen önerilmektedir. Bu fark istatistiksel olarak anlamlı değildir (Ki kare=0,217; $\mathrm{p}=0,641)$ (Tablo 5).

\section{Tartışma}

İnsanların sağlık arama davranışlarında kolay ve pratik bir çözüm olarak kullandıkları internet ortamındaki bilgilerin güvenilirliği toplum sağlığı açısından oldukça önemlidir. $\mathrm{Bu}$ araştırmada incelenen internet sitelerinin büyük çoğunluğunun kanıta dayalı bilgi içermediği tespit edilmiştir. Ayrıca bu araştırmaya göre araştırma içinde incelenmiş web sitelerinin yarıdan fazlasının uzman görüşü içermiyor olması durumu ve uzman görüşü içeren metinlerin de birçoğunun referans kullanmıyor oluşu web ortamında yer alan ve sağlıkla ilgili bilgi içeren metinlerin kaynağının ne olduğu ve nereden alındığının bilinmediğini ortaya çıkarmıştır (Tablo 2). Bu iki durum bir arada değerlendirildiğinde mevcut web sitelerinde yer alan doğru ya da yanlış bu bilgilerin kaynaklarının ne olduğu konusu "etik" bir sorun yaratmakla beraber, kaynağı belli olmayan bu bilgilerin doğruluğu da ayrı bir tartışma konusu olabilir.

İnternet aracılığı ile ulaşılan bilgiler, hastanın hastalığı ve kendisi ile ilgili alacağı kararı etkileyebilmektedir. Hasta, hastalığ ile ilgili hekim gözetimi altında olsa bile, durumuyla ilgili doğru ya da yanlış farklı seçenekleri de değerlendirebilmektedir. Ancak bu noktada, denetimsiz olarak gelişmeye devam etmekte olan bu bilgi havuzunun sağlık uygulamaları konusunda toplumu yanlış ve/veya yetersiz bilgilendirmesi endişesi ortaya çıkmaktadır [11].

Yapılan çalışmada, incelenen web sitelerinin yalnızca \%48'inin uzman görüşü içerdiği belirlenmiştir (Tablo 2). Konuyla ilgili yeterli donanıma ve bilgiye sahip olmayan kişilerin web sayfalarına yazdığı bilgilerin doğruluğu şüpheli olmakta ve konuya hâkim olmamalarından doğan yanlış yönlendirme olabilmektedir. $\mathrm{Bu}$ durum hastaların hastalıkları hakkında doğru bilgiye ulaşamamalarına ya da ulaşılan bilgiler yoluyla yanlış teşhis ve tedaviye yönlenmelerine yol açabilmektedir. Web sitelerinden bilgi edinen hastaların yaşadığı kafa karışıklığı, anksiyete ve sahte umutlara kapılma gibi durumlar hasta-hekim ilişkisini de olumsuz etkilemekte ve hastaların yeniden eğitilmesi gerektiğinde bunlar engel oluşturmaktadır. Web sitelerindeki bilgileri uzman hekimin vermesi hem hasta hem de o hasta ile karşılaşacak hekim için daha yararlı olacaktır.

Web sayfalarının sağlıkla ilgili bilgi vermesiyle birlikte, hastaların hastalığı ne olursa olsun, bir uzman hekime yönlendirmesi gerekmektedir. Web sitelerinin incelendiği çalışma sonuçlarına göre; web sayfalarının yalnızca \%59'u hastaları sağlık çalışanına yönlendirmiş̧ir (Tablo 2). Hastaları yönlendirmemek onların birtakım sebeplerle zarar görmesine neden olabilmektedir. Yazı dilinin hasta için yeterince anlaşılır olmaması, hastanın bilgi düzeyi, yazarın yanlış yönlendirmesi bu nedenlerden bazılarıdır. Ayrıca bazı web siteleri hastalara tedavi de önermektedir ama bu tedavi doğru olsa bile her hasta aynı olmadığından kullanan kişi de birtakım sorunlara yol açabilmektedir. Bu nedenle, web sitesini yazan bir uzman hekim olsa bile okuyucuyu veya hastayı uzmana yönlendirmesi yararlı olabilmektedir. 
Yapılan çalışmada incelenen web sitelerinin yaklaşık yarısının korumaya yönelik bilgiler içermediği saptanmıştır (Tablo 2). Sağlığın geliştirilmesinin temel öğelerinden biri olan hastalıklardan koruma hekimliğin en önemli amaçlarındandır. Bu açıdan bakıldığı zaman sağlık bilgileri içeren web sitelerinin özellikle bu konuda insanları bilinçlendirmede yetersiz kalabileceği öngörülebilir. Aynı zamanda internet, sağlık gibi insanların çok hassas davrandığı bir konuda öncelikli başvuru kaynağı olma noktasında hızla ilerlemektedir. Örneğin, ABD'de PEW Internet ve American Life projesinin verileri değerlendirildiğinde kullanıcıların \%80'inin sağlık sorunları için interneti kullandıkları görülmektedir. Günümüzde çok yaygın olarak kullanılan sosyal paylaşım sitelerinin birisinde de kronik hastalıklarla ilgili, hasta gruplarının oluşturduğu 1200 site olduğu bilinmektedir [12].

$\mathrm{Bu}$ veriler, internetin bu denli yaygın kullanıldı̆̆ korumaya dair güncel ayrıntıları içermesinin yararlı olabileceğini düşündürmektedir. Çünkü toplumda görülen hastalıkların ve kazaların pek çoğu, aslında, korunabilir olaylardır. Özellikle hastalıklardan korunmada asıl yapılacak işler, kişilerin kendilerinin alacakları önlemlerdir. O nedenle, kişiler kendi sağlıklarının değerini bilmeli ve onu korumaya çalışmalıdırlar. Böyle olmazsa, sağlık hizmetlerinin sunumu zorlaşır ve başarılı olunamaz. Ancak, kişilere kendi sağlıklarından sorumlu oldukları hakkındaki bilinci kazandırmak için gerekli eğitici çabayı göstermekte sağlık çalışanlarının sorumluluğudur. $\mathrm{Bu}$ nedenle web sayfalarının ve hekimin öncelikle hastalara hastalıklardan korunma ile ilgili bilgi vermesi gerekmektedir.

Sağlığın bir diğer vazgeçilmez unsuru olan teşhisle ilgili olarak yapılan araştırmada sitelerin büyük kısmının ziyaretçileri teşhise yönlendirdiği görülmektedir (Tablo 2). Teşhis hekim tarafından hastanın anamnezi, bulguları ve mevcut çeşitli tanı araçlarıyla konulabilen bir kavramdır. İnternet gibi sanal bir ortamda bu bileşenler olmadan hastaların teşhise yönlendirilmesi ciddi sağlık problemlerine yol açabilir ve yanlış tanı sebebiyle birçok hastalığın atlanmasına sebep olabilir.

Sağlık bilgisi paylaşılan sitelerde tedaviye yönelik bilgilere sıklıkla rastlanmaktadır. Yapılan araştırma sonucu elde edilen bulgular da web sitelerinde tedaviye yönlendirmenin ne kadar yüksek olduğunu göstermiştir (Tablo 2). İnternete ulaşımın çok kolay olduğu düşünülürse bireylerin istediklerinde tedaviye yönelik bilgilere ulaşmalarının da kolay olduğu öngörülebilir. Pautler ve arkadaşlarının yaptığı bir araştırmaya göre prostat kanseri olan 312 hastanın \%29'unun hastalıkları ile ilgili bilgi edinmek amacıyla interneti kullandığı, \%8'inin internetten edindikleri bilgiler sonucu tedavi kararına belirgin şekilde katkıda bulunduğu saptanmıştır [13].

Ancak web sayfalarının tümünün denetiminin mümkün olmaması nedeniyle bilgilerin ne kadar güvenilir olduğu tartışmalı bir durumdur. Bu nedenle internet üzerinden tedaviye yönelik edinilen bilgilerin sağlık açısından ne kadar yarar sağlayacağı düşünülmesi gereken bir konudur.

Tedaviye yönlendirme durumunda ticari kaygıların öne çıkarılması istenmeyen ve olmaması gereken bir durumdur. Ticari kaygılar öne çıkarıldığı takdirde tarafsızlık ortadan kalkacak ve çıkar ilişkisi araya girecektir. Çıkar ilişkisi ise hastanın sağlığına kavuşma sürecini olumsuz etkileyebilir. Araştırma sonucu elde edilen bulgular 1şığında ticari kayg1 duyma durumu düşük görülmektedir (Tablo 2). Bu olumlu bir sonuç gibi görülse de; ticari kaygılar üzerinden tedavi öneren web sitelerinin bulunuyor olmas1, insanların bu bilgilere ulaşıyor olması olumlu karşılanmaması gereken bir durumdur.

Çalışmanın bulguları incelendiğinde, sağlık arama davranışı için girilen sitelerin, çoğunlukla reklam ve sponsor içerikli olduğu görülmektedir (Tablo 2). Bu da bazı sorunları beraberinde getirmektedir. Örneğin, anahtar sözcük olarak girilen semptom sonucu ulaşılan tedavi ve korunma önerilerinin, gerçekten kanıta dayalı ve etkili olduğu için mi önerildiğini, yoksa kar amacı güdüldüğü için mi tavsiye edildiğini anlamak güçleşmektedir. 
Böylelikle insan sağlığını ya da hayatını tehlikeye atabilecek bilgi kirliliği konusu gündeme gelmektedir.

Yapılan araştırma sonucunda incelenen web sitelerinde resim, grafik, şema kullanılanların yüzdesi, kullanılmayanlara göre daha fazla bulunmasına rağmen bu ögelere yer veren web sitesi oranı beklenenden az belirlenmiştir (Tablo 1). Çünkü resim, grafik, şema gibi görsel ögelerden faydalanmanın eğitici anlamda, sadece yazıdan daha etkili olduğu ve yazıyı daha anlaşılır hale getirdiği günümüzde bilinen bir gerçektir [14]. Bu ögelerin halkın sağlık bilgisi edinme amaçlı sık kullandığ 1 bilinen bir metot olan internet sitelerinde daha çok yer alması gerektiği düşünülebilir.

İncelenen web siteleri arasında interaktif kurgusu bulunan sitelerin, bulunmayanlara göre daha az olduğu görülmüştür (Tablo 1). Bu sonuca göre, internetin yaygın kullanımı göz önüne alındığında, sağlık bilgisi edinme amaçlı kullanılan web sitelerinin aynı zamanda bir danışma aracı olarak kullanılamamasının, internet kullanıcıları açısından ciddi bir kısıtlılık yarattı̆̆g düşünülebilir.

$\mathrm{Bu}$ araştırmada sağlı bilgileri içeren web sitelerinden hastaları sosyal medyaya yönlendirenlerin, yönlendirmeyenlere göre daha fazla olduğu belirlenmiştir (Tablo 1). Sosyal medyanın internet kullanıcıları arasında yaygınlaşması, sağlık bilgisi edinme amacıyla kullanılmasının yaygınlaşmasını da beraberinde getirmiştir [15]. Ancak bu durum sosyal medyada var olan bilgilerin doğruluğu, kanıta dayalı bilgi içerme durumunu ve özellikle kronik hastalığa sahip bireyler açısından ne derece risk oluşturabileceği sorularını da beraberinde getirmektedir [16].

Araştırmanın kimi kısıtlılıkları bulunmaktadır. Web sitelerinin incelenmesi için tek bir arama motoru kullanılması, verilerin "anlık", "kesit" olarak toplanmış ve değerlendirilmiş olması, araştırılan anahtar sözcüklerin belirlenmesi sürecinde tek bir bilgi kaynağının kullanılmış olması başlıca kısıtlılıklar arasındadır.

Sitelerin güvenilir bulunma aşaması da araştırmacıların oluşturduğu bir değerlendirme biçimi olmuştur. Kimi sınırlılıkları olabilir.

Sonuç olarak; web sitelerinin değerlendirildiği bu araştırma kimi sınırlılıkları olmasına rağmen, toplumda sık görülen hastalık semptomları ile ilgili ulaşılabilen web sitelerinin içeriklerini incelemek ve değerlendirmek için bir zemin oluşturmuştur. İçerikte yer alan verilerin ve değerlendirmelerin konuyla ilgili bundan sonra yapılacak çalışmalara yol gösterebileceği düşünülmektedir.

\section{Kaynaklar}

1. Merriam Webster's Dictionary \& Thesaurus, 2008. Available from: http://www.merriam-webster.com/dictionary/internet. Accessed: 07.08.2014.

2. TDK Sözlük. Available from: http://www.tdk.gov.tr. Accessed: 07.08.2014.

3. Hanehalkı bilişim teknolojileri kullanım araştırması 2014 haber bülteni. Available from: http://www.tuik.gov.tr/PreHaberBultenleri.do?id=16198. Accessed: 10.12.2014.

4. Doyle DJ, Ruskin KJ, Engel TP. The internet and medicine; Past, Present and The future. Yale J Biol Med 1996; 69: 429-37.

5. Shepperd S,Charnock D,Gann B. Helping patients access high quality health information. Br Med J 1999; 319: 764-6.

6. Erer S. Kitle iletişim araçları ve tıp etiği. Düzce Üniversitesi Sağlık Bilimleri Enstitüsü Dergisi 2013; 3: 24-8.

7. Ulus T, Gürgan M. Sağlık alanında internet kullanımı ve halk sağlığı. Bozok Tıp Dergisi 2011; 2: 43-6.

8. Baker L, Wagner TH, Singer S, Bundorf MK. Use of the internet and e-mail for health care information, results from a national survey. JAMA 2003; 289: 240006.

9. Acar-Vaizoğlu S, Temel F, Alpan B, Bal İB, Bajin MD, Baş DF, Bitik O, Büke 
B, Güler Ç. Hacettepe Tıp Fakültesi Türkçe bölümü dönem 1 ve 4 öğrencilerinin bilgisayar kullanma özellikleri ve internetteki sağlı sitelerinde karşılaştıkları bilgilerin doğruluğu ve niteliği ile ilgili aradıkları kriterlerin belirlenmesi. Hacettepe Tip Dergisi 2006; 37: 56-63.

10. Available from: http://gs.statcounter.com/\#search_engine-ww-monthly-201307201407. Accessed: 07.08.2014.

11. Gülcü N, Bulut S. Bel ağrısı konusuna yönelik internet sitelerinin içerik analizi. Ağr1 2010; 22: 68-72.

12. Kayabalı K. İnternet ve sosyal medya evreninde sağlik. Available from: http://www.ikudergisi.com/IKU/images/stories/dergi_pdf/25/internet-sosyalmedya-saglik.pdf. Accessed: 07.08.2014.

13. Pautler SE, Tan JK, Dugas GR. Use of the internet for self-education by patients with prostate cancer. Urology 2001; 57: 230-3.

14. Piaget J, Vygotsky L, Bloom B, Dewey J, Bruner J, Ausubel D. Öğretim stratejileri, yöntemleri ve teknikleri. International Burch University, Education Faculty. Available from:http://tll.ibu.edu.ba/ass. Accessed: 07.08.2014.

15. Alshaikh F, Ramzan F, Rawaf S, Majeed A. Social network sites AS A mode TO collect health data: A systematic review. J Med Internet Res 2014; 16: 171.

16. Merolli M, Gray K, Martin-Sanchez F. Developing a framework to generate evidence of health outcomes from social media use in chronic disease management. Med 2013; 2: 3 . 